\title{
When Does the Winner Take All in Two-Sided Markets?
}

\author{
MINGCHUN SUN * \\ Global Economics, Lehman Brothers Asia Limited \\ EDISON TSE \\ Management Science and Engineering Department, Stanford University
}

\begin{abstract}
We study the diffusion of competing two-sided networks using a differential game framework. We find that whether the winner takes all depends on the participation behaviour of individual agents on both sides of the market. When individual agents tend to participate in only one network, one network will dominate the market. As the tendency for joining multiple networks increases, the possibility for two networks to co-exist in the long-run also increases. Thus the steady-state market share of competing two-sided networks can be very different depending on adopters' choice of "multi-homing" or "single-homing".
\end{abstract}

\section{Introduction}

The formal study of two-sided markets is a recent development in the field of economics with early contributions coming from Armstrong (2006), Caillaud and Jullien (2003), Park and Van Alstyne (2005), Rochet and Tirole (2003) and Schiff (2003) among others. In such a market, two groups of agents interact with each other via a common network platform and the value of participating in the network for agents in one group depends on the number of participants from the other group. Though the concept is new, two-sided markets are widely seen around us. For example, PC operating systems, online auction websites, shopping malls, dating services and nightclubs, and even language are all examples of two-sided markets. Most technology standards, such as VCR and DVD formats, modem standards, typewriter keyboard, etc. are two-sided networks.

An interesting phenomenon in two-sided markets is that in some of them, the winner seems to take the entire market, whereas in other markets multiple networks can co-exist and share the market. In Table 1, we show that in certain two-sided markets such as PC operating system, VCR format and typewriter keyboard, etc., one network takes all or almost all the market. On the other hand, in two-sided markets such as credit cards, we see four major payment networks: VISA, MasterCard, American Express and Discover. In the

\footnotetext{
* Mailing address: Flat E, 65 Floor, Tower 5, Sorrento, No. 1 Austin Road West, Kowloon, Hong Kong. Email: smchun2000@yahoo.com
} 
video game console market, there are three major game systems: Sony's PlayStation, Microsoft's Xbox, and Nintendo's GameCube. In the yellow directory market, multiple directories exist in almost every local market.

The variation in network dominance among two-sided markets indicates that "winnertakes-all” is not an inherent nature of two-sided markets. It thus brings interesting and important questions such as: What determines the dominance or co-existence of two-sided networks? What helps a particular network to dominate the market? What actions can network platform sponsors take in order to become dominant, or to avoid being driven out of the market? The answers to these questions are very important to network sponsors in forming strategic decisions. For example, a potential new network platform owner may decide not to enter a market if it allows only one network to survive. But the decision may be very different if the market it plans to enter allows multiple networks to co-exist. In this paper, we build differential games models to address these questions and identify the market context in which competing networks can co-exist.

The paper is organized as follows. We first introduce "two-sided markets" in section 2 together with a literature review. We present a dynamic pricing model for a monopolistic two-sided network to serve as a benchmark in Section 3. In section 4, we employ a differential games model to study the dynamic competition between two-sided networks, which gives conditions for various steady-state market share scenarios. Section 5 summarizes and concludes.

\begin{tabular}{|l|l|}
\hline Markets with one dominant network & Markets with multiple networks \\
\hline PC operating system & Payment card \\
VCR & Video games \\
Typewriter keyboard & Yellow directory \\
Colour TV system & Online auction markets \\
56 K dial-up modem & Shopping malls \\
Web browser & Dating clubs \\
Language (for example in China, U.S.) & CD/VCD/DVD standard \\
& TV networks \\
& Newspapers \\
& Language (for example in Hong Kong, \\
& Singapore, etc.) \\
\hline
\end{tabular}

Table 1: Network dominance in two-sided markets 


\section{Two-sided markets}

\section{$2.1 \quad$ Market structure}

In a two-sided market, two groups of agents interact with each other through a common network platform and the value of participating in the network for agents in one group depends on the number of participants from the other group. Such interdependence of value of participation represents cross-group network externalities.

In a two-sided market, the party who creates and services the network is called network platform sponsor. For example, Microsoft and Apple Computer are platform sponsors in the PC operating systems market; Sony, Microsoft and Nintendo are the sponsors of the video game console standards, etc. Since network platforms provide added-value to both sides of the market, the platform sponsor can charge fees to participants on both sides of the market. The charges could be either lump-sum, periodic or on per-transaction basis. Rochet and Tirole (2003) gives a comprehensive review of these different business models in two-sided markets.

When multiple network platforms exist, agents on either side can choose to (i) stay out of the network, (ii) participate in only one network, or (iii) participate in multiple networks. Scenario (ii) is referred to as single-homing and scenario (iii) as multi-homing (Armstrong, 2006; Armstrong and Wright, 2007; Caillaud and Jullien, 2001, 2003; and Rochet and Tirole, 2003).

It is important to note that single-homing (and multi-homing) is a concept at the individual agent level; not at the market level. Single-homing does not require that everybody has to be in the same network. While each individual agent joins only one network, different individuals may join different networks. For example, some PC users only use Windows while others only use Macintosh, which is equivalent to saying that some people single-home on Windows and others single-home on Macintosh. Meanwhile, multi-homing does not require that all agents join all networks. As long as an individual agent joins more than one network, she/he is multi-homing. For example, some people may carry both VISA and MasterCard cards while others may carry VISA and American Express cards.

Similarly, when some agents single-home in a two-sided market, others may multihome in the same market. For example, some game players only buy a PlayStation console (that is, single-homing) while others may purchase both PlayStation and Xbox (that is, multi-homing). On the game developer side, some write games for both PlayStation and Xbox (that is, multi-homing) while others may write games exclusively for Nintendo (that is, single-homing). Therefore, at the market level, single-homing and multi-homing is not clear-cut but really an issue of degree. Rochet and Tirole (2003) use "single-homing index" to characterize the phenomenon, which is basically a measure of agent's loyalty to a platform. The index for a specific platform is 0 when all "buyers" multi-home, and 1 when they all single-home. While the index is a continuous variable between 0 and 1 , most theoretical models on two-sided markets assume dichotomy for analytical convenience (Rochet and Tirole, 2003; and Armstrong, 2006).

An individual participant's choice of multi-homing can be endogenously or exogenously determined, from the view of the participants. For example, some network platform sponsors may require all participants on one or two sides of the market to sign exclusive participation contract (Armstrong, 2006; Armstrong and Wright, 2007; and 
Caillaud and Jullien, 2001, 2003), which forces its participants to single-home. On the other hand, the homing behaviour may also be endogenously determined by various elements of two-sided networks, especially the costs and benefits from homing on multiple platforms. The costs and benefits can be either pecuniary or non-pecuniary (for example, search cost, switch cost, technical difficulties, psychological benefit from participation in certain networks, etc.). For example, most PC users single-home (that is, use either Windows or Macintosh) either because of the high costs of purchasing two PCs or because of the technical complexity in learning and using two sets of PC operating systems. Most people single-home on web browsers (say, either Internet Explorer or Netscape) solely for convenience reasons, given that the browsers can usually be obtained free of charge. While some researchers explore the causes of single-homing and multi-homing behaviour (Armstrong and Wright, 2007), we take the homing behaviour in a particular two-sided market as given, and focus on how such behaviour affect network competition and survival in such a market.

In many two-sided markets, there is also a fourth type of agents which has not been discussed in the literature. We call them the distributors of a network. They are the agents that produce and sell network-specific products to network participants. For example, in the payment card network, banks such as Bank of America, Wells Fargo, Chase, etc. issue VISA or MasterCard cards to consumers and sign up merchants. They are neither the platform sponsor nor any side of the market. Instead, they are the distributors of the corresponding network (that is, VISA or MasterCard). Computer manufacturers such as Dell and Hewlett-Packard which produce and sell personal computers are distributors of the Windows operating system network. VCR player manufacturers such as Sony, Toshiba and JVC are distributors of the current VHS standard network.

Network distributors are not essential in a two-sided network because the platform sponsor may decide to take this role by itself. For example, Apple Computer manufactures Macintosh computers solely by itself and does not allow any third-party manufacturers. American Express had been issuing its Amex cards to cardholders solely by itself until 2004 when it started to allow distributors (that is, banks) to issue Amex-branded cards. In the video game console market, all the three major players, Sony, Microsoft and Nintendo, make the consoles in-house and do not have any distributor for their game system.

Although inessential to a two-sided network, network distributors may affect the diffusion speed of a network. The collective efforts of the distributors in signing up network participants and in improving the quality and features of the network could have a critical impact on the growth and even survival of a network, as will be shown later in the paper.

\section{$2.2 \quad$ Literature review}

Research on two-sided markets is an extension of the literature on network effects and network externalities. According to Katz and Shapiro (1985), "there are many products for which the utility that a user derives from consumption of the good increases with the number of other agents consuming the good". This definition refers primarily to network effects within one side of the market. For example, telephone subscribers derive more utility from the telephone network if more people subscribe to phone services. A subscriber will find the phone useless if nobody else installs it. This type of network effects is termed within-group effect. 
The recent literature on two-sided markets distinguishes cross-group from within-group network effects, focusing on the former. Rochet and Tirole (2006) and Roson (2005) provide extensive reviews of the literature. Related research include payment card systems (Rochet and Tirole, 2002; Schmalensee, 2002; and Wright, 2003a, 2003b, 2004), telecommunications (Armstrong, 2002; and Wright, 2002), advertising/yellow directories (Anderson and Coate, 2005; Dukes, 2003; Dukes and Gal-Or, 2003; and Rysman, 2004), matchmakers (Caillaud and Jullien, 2003), shopping malls (Pashigan, Gould and Prendergast, 2002).

The key assumption in modelling two-sided markets is how agents make decisions to join a particular network. Many researchers follow the "fulfilled expectation" (Katz and Shapiro, 1985) or "perfect foresight" (Shy, 2001) assumptions from the literature of network effects to explain the "winner-takes-all" phenomena. In those models, it is assumed that agents can correctly anticipate how many other agents will join a network, and make their own participation decisions based on such expectations. As a result of varying expectations of participants, multiple equilibria may exist: if participants expect one network to dominate, that network will turn out to be dominant because the expectations are assumed to be "fulfilled"; when people expect multiple networks to exist, the co-existence will also become true. If peoples' expectations "tip" toward one network, everybody will end up joining that network. Thus, the network will "corner" the market and become the dominating one (Farrell and Saloner, 1985; Katz and Shapiro, 1985; and Shapiro and Varian, 1999).

In these static equilibrium models, the positive feedback across the two-sides of the market is modelled through the "expected" size of the network, rather than the actual size. This is natural given the one-shot game in a static model. Since there is only one period, it is impossible to allow an agent's decision to be based on the previous period's state (that is, the number of participants on the other side of the market). Therefore, the positive feedback loop has to be modelled in a simultaneous decision-making process where each agent forms expectations of how many agents from the other side will participate in the network. A high expectation gives an agent a stronger incentive to participate, which demonstrates the positive feedback loop. To find the equilibrium for such static models, it is therefore assumed that all agents have the correct expectation (or perfect foresight of other agents' participation decisions).

Though the assumption of "fulfilled expectations" or "perfect foresight" is a convenient way of modelling network effects in a static equilibrium model, it reflects only one part of the story in a real marketplace. In many historic events, expectations tuned out to be incorrect, not only by ordinary consumers, but also by professionals such as industry analysts, corporate senior executives, etc. A notorious case was the expectation on IBM's OS/2. In the late 1980s, IBM made huge investments in its new proprietary operating system OS/2, in anticipation of replacing DOS/Windows as the next-generation predominant operating system in the PC market. It took substantial efforts to influence software developers and PC users to buy into the expectation (Carrol, 1993). Even Microsoft, the sponsor of the then predominating DOS/Windows system, had such an expectation. Microsoft had positioned its Windows 1.0/2.0/3.0 as temporary or "transitional" operating systems to OS/2 and allocated more resources on developing OS/2 together with IBM than on its Windows system. It "wasn't until Windows 3.0 sold a million copies that Gates decided that the project (developing Windows 3.1) was strategic" (Edstrom and Eller, 1998, p.100). However, IBM's OS/2 never really took off and it 
actually became a huge liability to IBM in late 1980s and early 1990s. If even professional forecasters and executives cannot form correct expectations, it is unrealistic to expect perfect foresight from ordinary consumers.

Though expectation does play an important role in an agent's decision, we assume in this paper that agents make their decisions on what they have seen, rather than what they expect to see in the market. In other words, they make participation decisions based on the actual size of the network, rather than the expected size. Such a decision process is incorporated into the differential game model as state transition equations or constraints of the optimal control problems. In the state transition equations, an agent's decision in the current period is based on the actual network size in the preceding period. Thus, the positive feedback loop across the two sides is modelled in an explicit and sequential way. Moreover, the differential games model allows network sponsors to control the diffusion processes by changing prices along a dynamic path. The objectives of the sponsors are to maximize the present value of cumulative profits, even if this may slow down the diffusion process.

The differential games are essentially optimal control models with a game structure (Dockner, Jorgensen, Van Long and Sorger, 2000). In the marketing literature, there is a stream of research on the optimal dynamic pricing policies for networks with positive demand externalities (another term for network effects). For example, Dhebar and Oren (1985, 1986) study the optimal dynamic pricing strategies for a monopolistic network where there are positive network effects among network participants. Some marketing researchers also employ the differential games approach. For example, Xie and Sirbu (1995) characterize the optimal dynamic pricing path for competing networks using openloop differential game framework. Our work differs from theirs in the following two aspects: (1) we study network competition in two-sided markets, in contrast to theirs which involve only one-sided network effects; (2) we focus on the steady-state market share and the factors affecting market dominance over the long-run, whereas they are interested in the pricing policy in a finite period. In fact, they build a finite horizon differential game model and simulate the game only within a short time period (10 periods), with a focus on the optimal pricing strategy.

The major contribution of our work is to show how the "homing" behaviour of network participants affects the long-term equilibrium of network competition. In particular, we find that based on the differential games model, one network is likely to dominate a twosided market if most network participants in that market tend to single-home. Our findings are consistent with Caillaud and Jullien (2001, 2003) who also find that single-homing is the most important determinant for market dominance, although they take a different modelling approach from ours. Ellison, Fudenberg and Mobius (2004) and Ellison and Fudenberg (2003) also study the conditions for network coexistence or "tipping" in twosided auction markets, although they find factors other than the homing behaviour (for example, market size) as the primary determinant.

Another contribution we make to the literature is the introduction of network distributors and the demonstration of their importance to the diffusion of a two-sided network. In existing literature, there is no explicit role for these distributors such as card issuers in the payment card networks and PC manufacturers in the PC OS networks. While the existence of these distributors and the network platform sponsors may make the network more like "multi-sided" (Evans, 2003a, 2003b), the lack of cross-group network externalities between distributors and other types of participants suggest that the former is 
not essential to two-sided networks, and should not be treated as a third side. Nevertheless, our models show that their existence could have significant impact on the diffusion of a two-sided network.

\section{Dynamic optimal pricing policy of a monopolistic two-sided network}

To set a benchmark for the differential game model, we first study an optimal control problem for a monopolistic two-sided network. Similar to Dhebar and Oren $(1985,1986)$, and Xie and Sirbu (1995), we assume the diffusion process is positively related to the magnitude of unsatisfied market demand.

Denote $X$ and $Y$ as the existing number of participants on the two sides of the market, and $D^{X}$ and $D^{Y}$ as the potential demands (that is, the number of people willing to join the network) on the two sides. To capture cross-group network effects and the price effect, we assume the potential demand functions to satisfy the following conditions:

$$
\begin{aligned}
& D^{X}=f\left(y, p_{x}\right), \quad \frac{d D^{X}}{d y}>0, \quad \frac{d D^{X}}{d p_{x}}<0 ; \\
& D^{Y}=g\left(x, p_{y}\right), \quad \frac{d D^{Y}}{d x}>0, \quad \frac{d D^{Y}}{d p_{y}}<0 .
\end{aligned}
$$

where $p_{x}, p_{y}$ are the prices/fees charged to participants for using the networks. To capture the saturation of the cross network effects, we also assume $\frac{d^{2} D^{X}}{d y^{2}}<0$ and $\frac{d^{2} D^{Y}}{d x^{2}}<0$.

We assume the diffusion speed to be proportional to unsatisfied demand, as shown below:

$$
\dot{X}=\alpha\left(D^{X}-X\right), \quad \dot{Y}=\beta\left(D^{Y}-Y\right) .
$$

Therefore, if the potential demand $\left(D^{X}\right.$ or $D^{Y}$ ) is higher than the actual demand $(X$ or $Y$ ), more people will join the network (at a rate of $\alpha$ or $\beta$ ); if the potential demand is lower than the actual demand, some participants will exit and stop using the network (also at a rate of $\alpha$ or $\beta$ ).

We assume the sponsor of the two-sided network profits from charging periodic fees to participants on both sides. Denote the fees charged to each participant at time $t$ as $p_{x}(t)$ and $p_{y}(t)$ and assume the costs of serving each participant at time $t$ are constant at $c_{x}$ and $c_{y}$. The profit function for the monopolistic network at time $t$ is:

$$
\pi(t)=\left(p_{x}(t)-c_{x}\right) x(t)+\left(p_{y}(t)-c_{y}\right) y(t) .
$$

The optimal control problem for the monopolistic network is

$$
\underset{p_{x}, p_{y}}{\operatorname{Max}} \int_{0}^{\infty} e^{-r t}\left[x(t)\left(p_{x}-c_{x}\right)+y(t)\left(p_{y}-c_{y}\right)\right] d t
$$

s.t.

$$
\dot{x}=\alpha\left[D^{x}\left(y, p_{x}\right)-x\right]
$$




$$
\begin{aligned}
& \dot{y}=\beta\left[D^{y}\left(x, p_{y}\right)-y\right] \\
& x(0)=x_{0}, \quad y(0)=y_{0}
\end{aligned}
$$

The problem can be solved by forming the current-value Hamiltonian

$$
H=\left[x(t)\left(p_{x}-c_{x}\right)+y(t)\left(p_{y}-c_{y}\right)\right]+m_{1} \alpha\left[D^{x}\left(y, p_{x}\right)-x\right]+m_{2} \beta\left[D^{y}\left(x, p_{y}\right)-y\right]
$$

with the following necessary conditions for optimality

(3) $\frac{\partial H}{\partial p_{x}}=x-\frac{d D^{x}\left(y, p_{x}\right)}{d p_{x}} m_{1} \alpha=0$

(4) $\frac{\partial H}{\partial p_{y}}=y-\frac{d D^{y}\left(x, p_{y}\right)}{d p_{y}} m_{2} \beta=0$

(5) $\quad \dot{m}_{1}=r m_{1}-\frac{\partial H}{\partial x}=m_{1}(r+\alpha)-p_{x}+c_{x}-\frac{d D^{y}\left(x, p_{y}\right)}{d x} m_{2} \beta$

(6) $\dot{m}_{2}=r m_{2}-\frac{\partial H}{\partial y}=m_{2}(r+\beta)-p_{y}+c_{y}-\frac{d D^{x}\left(y, p_{x}\right)}{d x} m_{1} \alpha$

and transversality conditions $\lim _{t \rightarrow \infty} e^{-r t} m_{1}(t)=0, \quad \lim _{t \rightarrow \infty} e^{-r t} m_{2}(t)=0$.

The solutions can be found by solving the $4 \times 4$ two-point boundary value problem formed by (1), (2), (5) and (6), where $p_{x}(t)$ and $p_{y}(t)$ are determined by (3) and (4). The state variables $x$ and $y$ have initial values while the co-state variables are treated as having terminal values if the system has a steady-state.

We consider the following forms of the potential demand functions:

$$
D^{x}=b_{1} \sqrt{y(t)}-d_{1} p_{x}^{2}
$$

$$
D^{y}=b_{2} \sqrt{x(t)}-d_{2} p_{y}^{2}
$$

which satisfy the properties outlined earlier. $b_{1}$ and $b_{2}$ can be viewed as the parameters which characterize the intrinsic value of the network to its participants, or the quality of the network service/products. We use quadratic forms for prices by assuming that the higher the price, the sharper the drop in demand. The non-linear form in prices also helps us to avoid bang-bang solutions in the optimal control problem.

It is easy to see that for sufficiently small values of $b_{1}$ and $b_{2}$, the steady state for the system is $x(t)=y(t)=0$ if the network starts from a small size. In other words, if the intrinsic value of the network is too small, it is very difficult for the network to overcome the “chicken and egg” problem (Caillaud and Jullien, 2003; Rochet and Tirole, 2003; Sun, 2006; and Sun and Tse, 2007) created by network externalities. However, for sufficiently large values of $b_{1}$ and $b_{2}$ and sufficiently large initial network sizes, the network should be able to surpass the critical mass and grow over time.

Given the complexity of the resulting dynamic system from the optimal conditions, we have to use Matlab package $b v p 4 c$ to find numerical solutions, assuming the following initial conditions and parameter values: 


$$
\alpha=0.1, \beta=0.1, b_{1}=40, b_{2}=40, c_{x}=2, c_{y}=2, d_{1}=1, d_{2}=1, r=0.05, x(0)=y(0)=100 .
$$

The numerical simulation shows that the monopolistic network reaches a steady state in the long-run. As the network grows, optimal pricing also increases until the steady state is reached (see Figure 1). The existence of a steady state is due mostly to the saturation of network effects, which reduces the speed of diffusion as the network grows to a larger size. The saturation effects are reflected in the concavity of the diffusion functions in the number of network participants. As long as the prices are positive, the concavity will eventually bring the diffusion speed down to zero, at which point the steady state is reached.

Using prices as controls for profit optimization affects the level of steady-state, as is shown in Figure 2 where assumptions on participants' sensitivity to price are changed. Differences in product benefits (parameters $b_{1}$ and $b_{2}$ ) also have significant impact on the steady-state network size and optimal pricing (see Figure 3).

\section{Differential games between competing networks}

\subsection{Demand functions}

When two networks compete for market share, the demand functions for each of them will be affected by both the price and the size of the rival network. The former is due to the substitution effect and the latter to network effect. This is reflected in the demand functions

$$
\begin{aligned}
& D_{i}^{x}=f\left(y_{i}, y_{j}, p_{i x}, p_{j x}\right), \quad i, j=1,2 \\
& D_{i}^{y}=g\left(x_{i}, x_{j}, p_{i y}, p_{j y}\right), \quad i, j=1,2
\end{aligned}
$$

with the following properties:

$$
\begin{aligned}
& \frac{d D_{i}^{x}}{d y_{i}}>0, \quad \frac{d D_{i}^{x}}{d y_{j}} \leq 0, \quad \frac{d D_{i}^{x}}{d p_{i x}}<0, \quad \frac{d D_{i}^{x}}{d p_{j x}} \geq 0, \quad i, j=1,2 \\
& \frac{d D_{i}^{y}}{d x_{i}}>0, \quad \frac{d D_{i}^{y}}{d x_{j}} \leq 0, \quad \frac{d D_{i}^{y}}{d p_{i y}}<0, \quad \frac{d D_{i}^{y}}{d p_{j y}} \geq 0, \quad i, j=1,2 .
\end{aligned}
$$

These properties imply that (1) the participant base of the rival network negatively affects the demand for own network since participants may be attracted to a network with larger network effects; and (2) prices charged by the rival network positively affect the demand for own network as participants are price sensitive and the two networks are close substitutes.
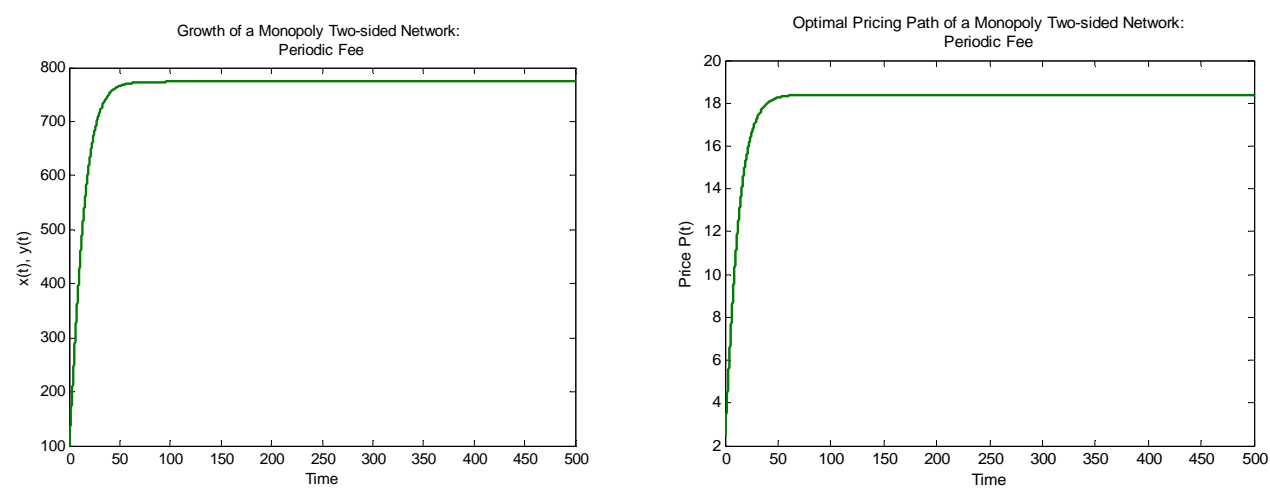


\section{Figure 1: The growth and optimal pricing path of a monopolistic network}
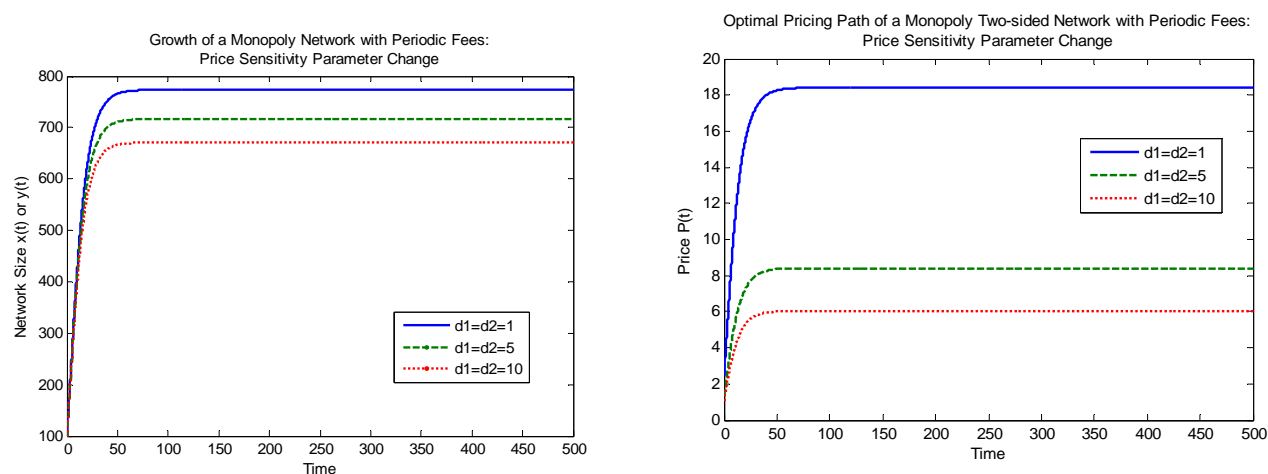

Figure 2: The impact of price sensitivity on network growth and optimal pricing
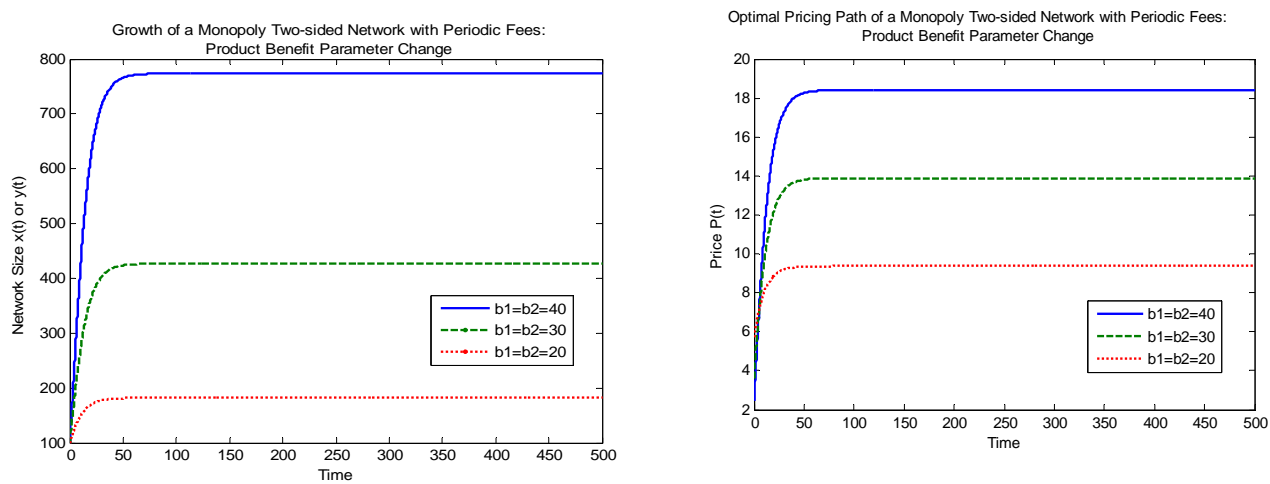

Figure 3: The impact of product benefits on network growth and optimal pricing

We expect the impact of a rival network's participant base on a network's potential demand is larger in single-homing scenario than in multi-homing one, because in the latter, participants do not have to give up one network to join the other. Thus, participants care more about the absolute benefit of joining a network than the relative benefits between the two. If the rival network has a larger participant base, a participant can always choose to join both networks without having to give up the existing one. But in the single-homing case, a network with a larger market share may attract lots of participants from its rival. To capture this effect, we consider specific functional forms of adoption dynamics, modified from the monopolistic model (that is equations (7) and (8)):

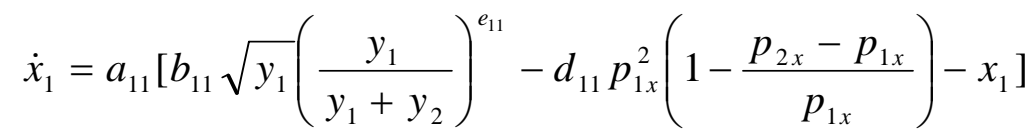

(10) $\dot{y}_{1}=a_{12}\left[b_{12} \sqrt{x_{1}}\left(\frac{x_{1}}{x_{1}+x_{2}}\right)^{e_{12}}-d_{12} p_{1 y}^{2}\left(1-\frac{p_{2 y}-p_{1 y}}{p_{1 y}}\right)-y_{1}\right]$ 
(11) $\dot{x}_{2}=a_{21}\left[b_{21} \sqrt{y_{2}}\left(\frac{y_{2}}{y_{1}+y_{2}}\right)^{e_{21}}-d_{21} p_{2 x}^{2}\left(1-\frac{p_{1 x}-p_{2 x}}{p_{2 x}}\right)-x_{2}\right]$

(12) $\dot{y}_{2}=a_{22}\left[b_{22} \sqrt{x_{2}}\left(\frac{x_{2}}{x_{1}+x_{2}}\right)^{e_{22}}-d_{22} p_{2 y}^{2}\left(1-\frac{p_{1 y}-p_{2 y}}{p_{2 y}}\right)-y_{2}\right]$

where $x_{i}, y_{i}, i=1,2$ are the numbers of participants of network $i$, and $e_{i k}, i, k=1,2$ are the parameters representing the degree of single-homing on network $i$ for the participants on the $k$-side.

Comparing (9) with (7), there are two extra factors $\left(\frac{y_{1}}{y_{1}+y_{2}}\right)^{e_{11}}$ and $\left(1-\frac{p_{2 x}-p_{1 x}}{p_{1 x}}\right)$. Since $\left(\frac{y_{1}}{y_{1}+y_{2}}\right)$ represents market share of network 1 on the $y$-side, this term is 1 when $y_{2}$ is zero. In that case, (9) has the same terms as in the monopoly case (7) if we neglect the pricing part. When $y_{2}$ is positive, the value of $\left(\frac{y_{1}}{y_{1}+y_{2}}\right)$ is always between 0 and 1 . The larger the number of existing participants of network 2 (that is $y_{2}$ ), the smaller the value of $\left(\frac{y_{1}}{y_{1}+y_{2}}\right)$, thus the smaller the potential demand for network 1 on the $x$-side. When $e_{11}=1$, demand for network 1 on the $x$-side is linear in $\left(\frac{y_{1}}{y_{1}+y_{2}}\right)$, which represents strong negative impact of rival network's market share on own demand. When $e_{11}=0,\left(\frac{y_{1}}{y_{1}+y_{2}}\right)^{e_{11}}=1$ for any value of $\left(\frac{y_{1}}{y_{1}+y_{2}}\right)$, which means that market share has no impact on demand. This represents an extreme case of the multi-homing scenario in which the two networks are not-competitive at all in terms of product benefits and network effects. In that case, only prices matter. When $e_{11}$ gradually reduces from 1 to $0,\left(\frac{y_{1}}{y_{1}+y_{2}}\right)^{e_{11}}$ becomes very close to 1 for a wider range of values of $\left(\frac{y_{1}}{y_{1}+y_{2}}\right)$, meaning that the existing market share on the $y$-side has less and less impact on the potential demand on the $x$-side. Therefore, as $e_{11}$ changes from 1 to 0 , the demand function changes from more single-homing to more multi-homing.

The second extra factor in (9), $\left(1-\frac{p_{2 x}-p_{1 x}}{p_{1 x}}\right)$, represents the cross pricing effect. Since participants are price sensitive, they are likely to choose the network with lower prices if everything else is the same. Therefore, the demand for a network will be lower if the rival network charges lower prices, and vice versa. This is reflected in $\left(1-\frac{p_{2 x}-p_{1 x}}{p_{1 x}}\right)$ which represents relative price competitiveness. When $p_{2 x}=p_{1 x}$, this 
extra term is equal to 1 . In other words, if the rival charges the same prices, there is no change in potential demand as compared to the monopoly case. If the rival charges lower price, the (negative) price difference is captured by $\left(\frac{p_{2 x}-p_{1 x}}{p_{1 x}}\right)$ in percentage form. Since $\left(1-\frac{p_{2 x}-p_{1 x}}{p_{1 x}}\right)>1$ when $p_{2 x}<p_{1 x}$, the potential demand for network 1 on the $x$ side is smaller as shown in (9) as compared to the monopoly case in (7). This type of positive cross price sensitivity also holds when the rival charges higher prices, and it is a common assumption in the literature.

\subsection{The differential game}

When the adoption dynamics follow (9)-(12), the diffusion of a network is affected not only by its own pricing policy, but also by that of the rival network. Similarly, its pricing policy also affects the diffusion of the rival network which faces the same problem. To maximize profits, the two networks may engage in a pricing game in which both choose the best possible pricing policy, given rival's policy. When neither has an incentive to deviate from its optimal policy, a Nash Equilibrium is reached (Dockner, Jorgensen, Van Long and Sorger 2000). We model this in an infinite horizon open-loop differential game.

Specifically, network 1 faces the following optimization problem:

$$
\begin{aligned}
& \underset{p_{1 x}, p_{1 y}}{\operatorname{Max}} \int_{0}^{\infty} e^{-r t}\left[x_{1}(t)\left(p_{1 x}-c_{1 x}\right)+y_{1}(t)\left(p_{1 y}-c_{1 y}\right)\right] d t \\
& \text { s.t. (9) - (12) } \\
& \text { and with initial conditions } x_{1}(0)=x_{10}, y_{1}(0)=y_{10}, x_{2}(0)=x_{20}, y_{2}(0)=y_{20}
\end{aligned}
$$

The current value Hamiltonian is

$$
\begin{aligned}
H_{1}=x_{1} & \left(p_{1 x}-c_{1 x}\right)+y_{1}\left(p_{1 y}-c_{1 y}\right) \\
& +m_{1} a_{11}\left[b_{11} \frac{y_{1}^{0.5+e_{11}}}{\left(y_{1}+y_{2}\right)^{e_{11}}}-2 d_{11} p_{1 x}^{2}+d_{11} p_{1 x} p_{2 x}-x_{1}\right] \\
& +m_{2} a_{12}\left[b_{12} \frac{x_{1}^{0.5+e_{12}}}{\left(x_{1}+x_{2}\right)^{e_{12}}}-2 d_{12} p_{1 y}^{2}+d_{12} p_{2 y} p_{1 y}-y_{1}\right] \\
& +m_{3} a_{21}\left[b_{21} \frac{y_{2}^{0.5+e_{21}}}{\left(y_{1}+y_{2}\right)^{e_{21}}}-2 d_{21} p_{2 x}^{2}+d_{21} p_{1 x} p_{2 x}-x_{2}\right] \\
& +m_{4} a_{22}\left[b_{22} \frac{x_{2}^{0.5+e_{22}}}{\left(x_{1}+x_{2}\right)^{e_{22}}}-2 d_{22} p_{2 y}^{2}+d_{22} p_{1 y} p_{2 y}-y_{2}\right]
\end{aligned}
$$

where $m_{i}, i=1,2,3,4$ are the four co-state variables corresponding to the state variables $x_{1}, y_{1}, x_{2}, y_{2}$.

On the other hand, network 2 faces a similar optimal control problem:

$$
\underset{p_{2 x}, p_{2 y}}{\operatorname{Max}} \int_{0}^{\infty} e^{-r t}\left[x_{2}(t)\left(p_{2 x}-c_{2 x}\right)+y_{2}(t)\left(p_{2 y}-c_{2 y}\right)\right] d t
$$

s.t. $(9)-(12)$

and with initial conditions: $x_{1}(0)=x_{10}, y_{1}(0)=y_{10}, x_{2}(0)=x_{20}, y_{2}(0)=y_{20}$.

The current value Hamiltonian for this problem is 


$$
\begin{aligned}
H_{2}= & x_{2}\left(p_{2 x}-c_{2 x}\right)+y_{2}\left(p_{2 y}-c_{2 y}\right) \\
& +\lambda_{1} a_{21}\left[b_{21} \frac{y_{2}^{0.5+e_{21}}}{\left(y_{1}+y_{2}\right)^{e_{21}}}-2 d_{21} p_{2 x}^{2}+d_{21} p_{1 x} p_{2 x}-x_{2}\right] \\
& +\lambda_{2} a_{22}\left[b_{22} \frac{x_{2}^{0.5+e_{22}}}{\left(x_{1}+x_{2}\right)^{e_{22}}}-2 d_{22} p_{2 y}^{2}+d_{22} p_{1 y} p_{2 y}-y_{2}\right] \\
& +\lambda_{3} a_{11}\left[b_{11} \frac{y_{1}^{0.5+e_{11}}}{\left(y_{1}+y_{2}\right)^{e_{11}}}-2 d_{11} p_{1 x}^{2}+d_{11} p_{1 x} p_{2 x}-x_{1}\right] \\
& +\lambda_{4} a_{12}\left[b_{12} \frac{x_{1}^{0.5+e_{12}}}{\left(x_{1}+x_{2}\right)^{e_{12}}}-2 d_{12} p_{1 y}^{2}+d_{12} p_{2 y} p_{1 y}-y_{1}\right]
\end{aligned}
$$

where $\lambda_{i}, i=1,2,3,4$ are the four co-state variables corresponding to the state variables $x_{2}, y_{2}, x_{1}, y_{1}$.

The optimality conditions for both $H_{1}$ and $H_{2}$ require four differential equations on $m_{i}, i=1,2,3,4$ and four on $\lambda_{i}, i=1,2,3,4$.

$$
\begin{aligned}
\dot{m}_{1}= & r m_{1}-\frac{\partial H_{1}}{\partial x_{1}}=m_{1}\left(r+a_{11}\right)-p_{1 x}+c_{11} \\
& -\frac{m_{2} a_{12} b_{12}\left[0.5 x_{1}^{0.5+e_{12}}+\left(0.5+e_{12}\right) x_{1}^{e_{12}-0.5} x_{2}\right]}{\left(x_{1}+x_{2}\right)^{e_{12}+1}}+\frac{m_{4} a_{22} b_{22} e_{22} x_{2}^{0.5+e_{22}}}{\left(x_{1}+x_{2}\right)^{e_{22}+1}}
\end{aligned}
$$

$$
\begin{aligned}
\dot{m}_{2}= & r m_{2}-\frac{\partial H_{1}}{\partial y_{1}}=m_{2}\left(r+a_{12}\right)-p_{1 y}+c_{12} \\
& -\frac{m_{1} a_{11} b_{11}\left[0.5 y_{1}^{0.5+e_{11}}+\left(0.5+e_{11}\right) y_{1}^{e_{11}-0.5} y_{2}\right]}{\left(y_{1}+y_{2}\right)^{e_{11}+1}}+\frac{m_{3} a_{21} b_{21} e_{21} y_{2}^{0.5+e_{21}}}{\left(y_{1}+y_{2}\right)^{e_{21}+1}}
\end{aligned}
$$

$$
\begin{array}{r}
\dot{m}_{3}=r m_{3}-\frac{\partial H_{1}}{\partial x_{2}}=m_{3}\left(r+a_{21}\right)+\frac{m_{2} a_{12} b_{12} e_{12} x_{1}^{0.5+e_{12}}}{\left(x_{1}+x_{2}\right)^{e_{12}+1}} \\
-\frac{m_{4} a_{22} b_{22}\left[\left(0.5+e_{22}\right) x_{1} x_{22}^{e_{22}-0.5}+0.5 x_{2}^{e_{22}+0.5}\right]}{\left(x_{1}+x_{2}\right)^{e_{22}+1}}
\end{array}
$$

$$
\begin{array}{r}
\dot{m}_{4}=r m_{4}-\frac{\partial H_{1}}{\partial y_{2}}=m_{4}\left(r+a_{22}\right)+\frac{m_{1} a_{11} b_{11} e_{11} y_{1}^{e_{11}+0.5}}{\left(y_{1}+y_{2}\right)^{e_{11}+1}} \\
-\frac{m_{3} a_{21} b_{21}\left[\left(0.5+e_{21}\right) y_{1} y_{2}^{e_{21}-0.5}+0.5 y_{2}^{e_{21}+0.5}\right]}{\left(y_{1}+y_{2}\right)^{e_{21}+1}}
\end{array}
$$

$$
\begin{aligned}
\dot{\lambda}_{1}= & r \lambda_{1}-\frac{\partial H_{2}}{\partial x_{2}}=\lambda_{1}\left(r+a_{21}\right)-p_{2 x}+c_{21} \\
& -\frac{\lambda_{2} a_{22} b_{22}\left[0.5 x_{2}^{0.5+e_{22}}+\left(0.5+e_{22}\right) x_{2}^{e_{22}-0.5} x_{1}\right]}{\left(x_{1}+x_{2}\right)^{e_{22}+1}}+\frac{\lambda_{4} a_{12} b_{12} e_{12} x_{1}^{0.5+e_{12}}}{\left(x_{1}+x_{2}\right)^{e_{12}+1}}
\end{aligned}
$$




$$
\begin{aligned}
\dot{\lambda}_{2}= & r \lambda_{2}-\frac{\partial H_{2}}{\partial y_{2}}=\lambda_{2}\left(r+a_{22}\right)-p_{2 y}+c_{22} \\
& -\frac{\lambda_{1} a_{21} b_{21}\left[0.5 y_{2}^{0.5+e_{21}}+\left(0.5+e_{21}\right) y_{2}^{e_{21}-0.5} y_{1}\right]}{\left(y_{1}+y_{2}\right)^{e_{21}+1}}+\frac{\lambda_{3} a_{11} b_{11} e_{11} y_{1}^{0.5+e_{11}}}{\left(y_{1}+y_{2}\right)^{e_{11}+1}} \\
\dot{\lambda}_{3}= & r \lambda_{3}-\frac{\partial H_{2}}{\partial x_{1}}=\lambda_{3}\left(r+a_{11}\right)+\frac{\lambda_{2} a_{22} b_{22} e_{22} x_{2}^{0.5+e_{22}}}{\left(x_{1}+x_{2}\right)^{e_{22}+1}} \\
& -\frac{\lambda_{4} a_{12} b_{12}\left[\left(0.5+e_{12}\right) x_{2} x_{1}^{e_{12}-0.5}+0.5 x_{1}^{0.5+e_{12}}\right]}{\left(x_{1}+x_{2}\right)^{e_{12}+1}} \\
\dot{\lambda}_{4}= & r \lambda_{4}-\frac{\partial H_{2}}{\partial y_{1}}=\lambda_{4}\left(r+a_{12}\right)+\frac{\lambda_{1} a_{21} b_{21} e_{21} y_{2}^{0.5+e_{21}}}{\left(y_{1}+y_{2}\right)^{e_{21}+1}} \\
& -\frac{\lambda_{3} a_{11} b_{11}\left[\left(0.5+e_{11}\right) y_{2} y_{1}^{e_{11}-0.5}+0.5 y_{1}^{0.5+e_{11}}\right]}{\left(y_{1}+y_{2}\right)^{e_{11}+1}}
\end{aligned}
$$

The control variables (that is the prices) can be determined from the following optimality conditions:

$$
\begin{aligned}
& \frac{\partial H_{1}}{\partial p_{1 x}}=x_{1}-4 m_{1} a_{11} d_{11} p_{1 x}+\left(m_{1} a_{11} d_{11}+m_{3} a_{21} d_{21}\right) p_{2 x}=0 \\
& \quad \Rightarrow \quad p_{1 x}=\frac{x_{1}+\left(m_{1} a_{11} d_{11}+m_{3} a_{21} d_{21}\right) p_{2 x}}{4 m_{1} a_{11} d_{11}} \\
& \frac{\partial H_{1}}{\partial p_{1 y}}=y_{1}-4 m_{2} a_{12} d_{12} p_{1 y}+\left(m_{2} a_{12} d_{12}+m_{4} a_{22} d_{22}\right) p_{2 y}=0
\end{aligned}
$$

$$
\Rightarrow \quad p_{1 y}=\frac{y_{1}+\left(m_{2} a_{12} d_{12}+m_{4} a_{22} d_{22}\right) p_{2 y}}{4 m_{2} a_{12} d_{12}}
$$

$$
\frac{\partial H_{2}}{\partial p_{2 x}}=x_{2}-4 \lambda_{1} a_{21} d_{21} p_{2 x}+\left(\lambda_{1} a_{21} d_{21}+\lambda_{3} a_{11} d_{11}\right) p_{1 x}=0
$$

$$
\Rightarrow \quad p_{2 x}=\frac{x_{2}+\left(\lambda_{1} a_{21} d_{21}+\lambda_{3} a_{11} d_{11}\right) p_{1 x}}{4 \lambda_{1} a_{21} d_{21}}
$$

$$
\begin{gathered}
\frac{\partial H_{2}}{\partial p_{2 y}}=y_{2}-4 \lambda_{2} a_{22} d_{22} p_{2 y}+\left(\lambda_{2} a_{22} d_{22}+\lambda_{4} a_{12} d_{12}\right) p_{1 y}=0 \\
\Rightarrow \quad p_{2 y}=\frac{y_{2}+\left(\lambda_{2} a_{22} d_{22}+\lambda_{4} a_{12} d_{12}\right) p_{1 y}}{4 \lambda_{2} a_{22} d_{22}}
\end{gathered}
$$

Equations (21)-(24) can be used to find the four pricing variables, which are then substituted into transition equations (9)-(12) and the equations governing the co-state variables (13)-(20). Therefore, we have a system of 12 differential equations (9)-(20) with 12 dynamic variables, four of which have initial values and the other eight can be thought 
of as having terminal values if the steady state exists in the infinite horizon problem. Therefore, we are facing a two-point boundary value problem (TPBVP) with 12 equations and 12 unknowns. Since the differential equations are non-linear in the state variables, it is impossible to find analytical solutions. So we use Matlab bvp4c to find numerical solutions. For all simulations below, we assume the following parameter values, unless otherwise stated:

$$
\begin{aligned}
& a_{11}=0.1 ; a_{12}=0.1 ; a_{21}=0.1 ; a_{22}=0.1 ; b_{11}=40 ; b_{12}=40 ; b_{21}=40 ; b_{22}=40 ; \\
& c_{11}=2 ; c_{12}=2 ; c_{21}=2 ; c_{22}=2 ; d_{11}=1 ; d_{12}=1 ; d_{21}=1 ; d_{22}=1 ; r=0.05 ;
\end{aligned}
$$

\subsection{Network co-existence}

We first look at the case when participants tend to single-home on both sides. We set $e_{i k}=1$ for all $i, k=1,2$ and consider the case where the two sides are symmetric, that is, the two sides start with the same initial conditions and parameter values. Since the pricing policies and the steady-states for both sides are the same, we can focus on the comparison between the two networks instead of getting involved in the two sides of a single network.

When two competing networks start at the same initial conditions, the optimal pricing policies and the growth paths of the two networks are the same (Figure 4). In other words, they will co-exist over the long-term. However, the co-existence is not stable because a slight change in the initial condition will change the diffusion dynamics drastically. In the left chart of Figure 5, we see that if the initial conditions of network 2 are changed from 100 to 99 on both sides, the steady states diverge between the two competing networks. Network 1, which still starts from 100 on both sides, will grab almost all the market share. Network 2, which is only $1 \%$ smaller than network 1 initially, will end up with only a tiny fraction of the market. When the gap of the initial sizes widens, the steady states of the two competing networks remain the same as in the scenario of 100 vs. 99 (see the right chart of Figure 5). In both cases, though network 2 will not completely disappear from the market, its tiny market share provides similar insights to those from the linear dynamic systems model of Sun (2006) and Sun and Tse (2006): if participants tend to single-home on both sides, it is most likely that one network will completely dominate the market (with a significantly large market share).

However, the long-run competition outcome changes when participants' tendency for multi-homing increases. When participants' tendency for multi-homing $e_{i k}$ changes from 1 to 0.6 for all $i$ and $k$ and the two competing networks start from the initial conditions $x_{1}(0)=y_{1}(0)=100, x_{2}(0)=y_{2}(0)=99$, the steady-states of the two competing networks eventually converge to each other, regardless of the gap in their initial conditions (Figure 6).

As the tendency for multi-homing increases, that is when $e_{i k}$ decreases even further, it becomes easier for the two networks to co-exist. This is also shown in Figure 6 where we present the results for $e_{i k}=0.5$ for $i, k=1,2$. Similar to the case when $e_{i k}=0.6$ for $i, k=1,2$, the two competing networks will co-exist and equally divide the market shares in the longrun. But the speed of convergence is much faster now: while it takes about 2500 periods for the two networks to reach steady-states when $e_{i k}=0.6$ for $i, k=1,2$, it only takes about 250 periods when $e_{i k}=0.5$ for $i, k=1,2$. 
The numerical solutions to the differential games indicate that, as participants' tendency to multi-homing increases, the importance of initial condition to network diffusion reduces. When participants tend to multi-home, it is possible for multiple networks to co-exist. If the two networks have similar attributes (that is, parameter values), it is likely they will equally share the market even if one network may come to the market much earlier than the other.

The diffusion process is clearly affected by participants' tendency to multi-homing. As seen in Figure 6, the greater the tendency to multi-homing, the faster the two competing networks converge to their steady-states. If the converging process takes too long, as in the case of $e_{i k}=0.6$ for $i, k=1,2$, we may never see the steady-state in real life because new technologies and players are likely to enter the market before the steady-state is reached. In that case, we will only see an early portion of the long-term dynamic diffusion path.
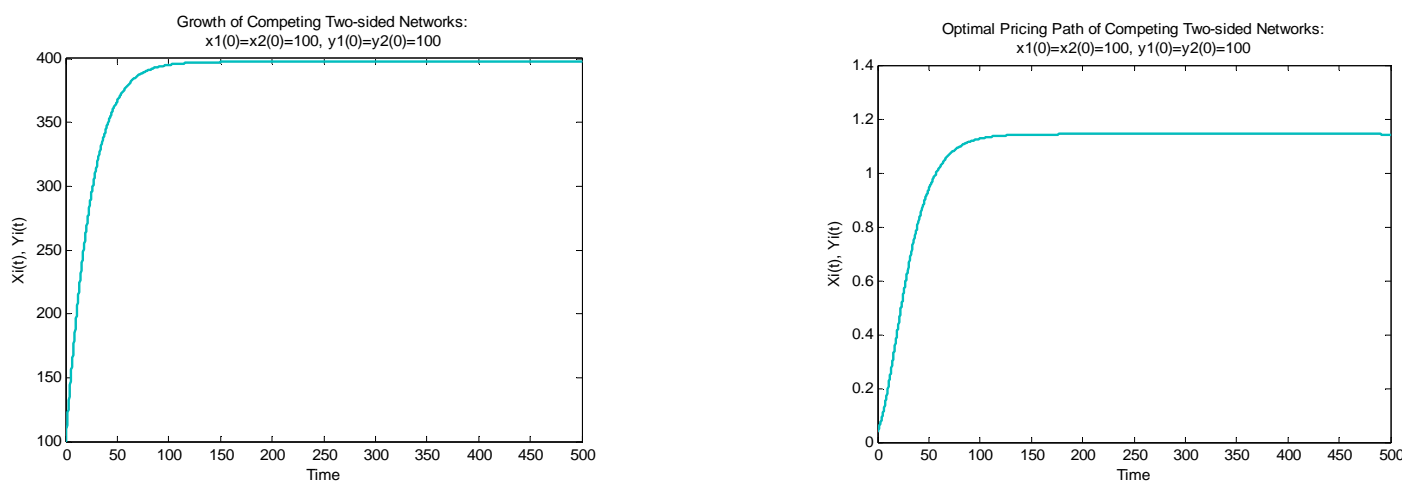

Figure 4: Growth and optimal pricing path of competing two-sided networks with equal and symmetric initial conditions
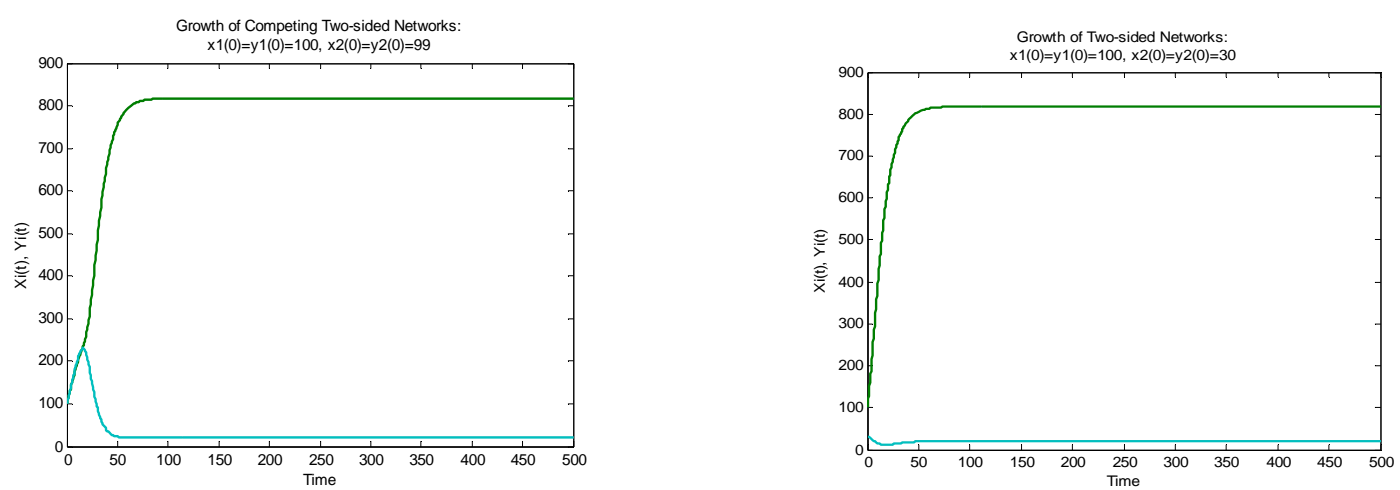

Figure 5: Growth of competing two-sided networks: Single-homing scenario 

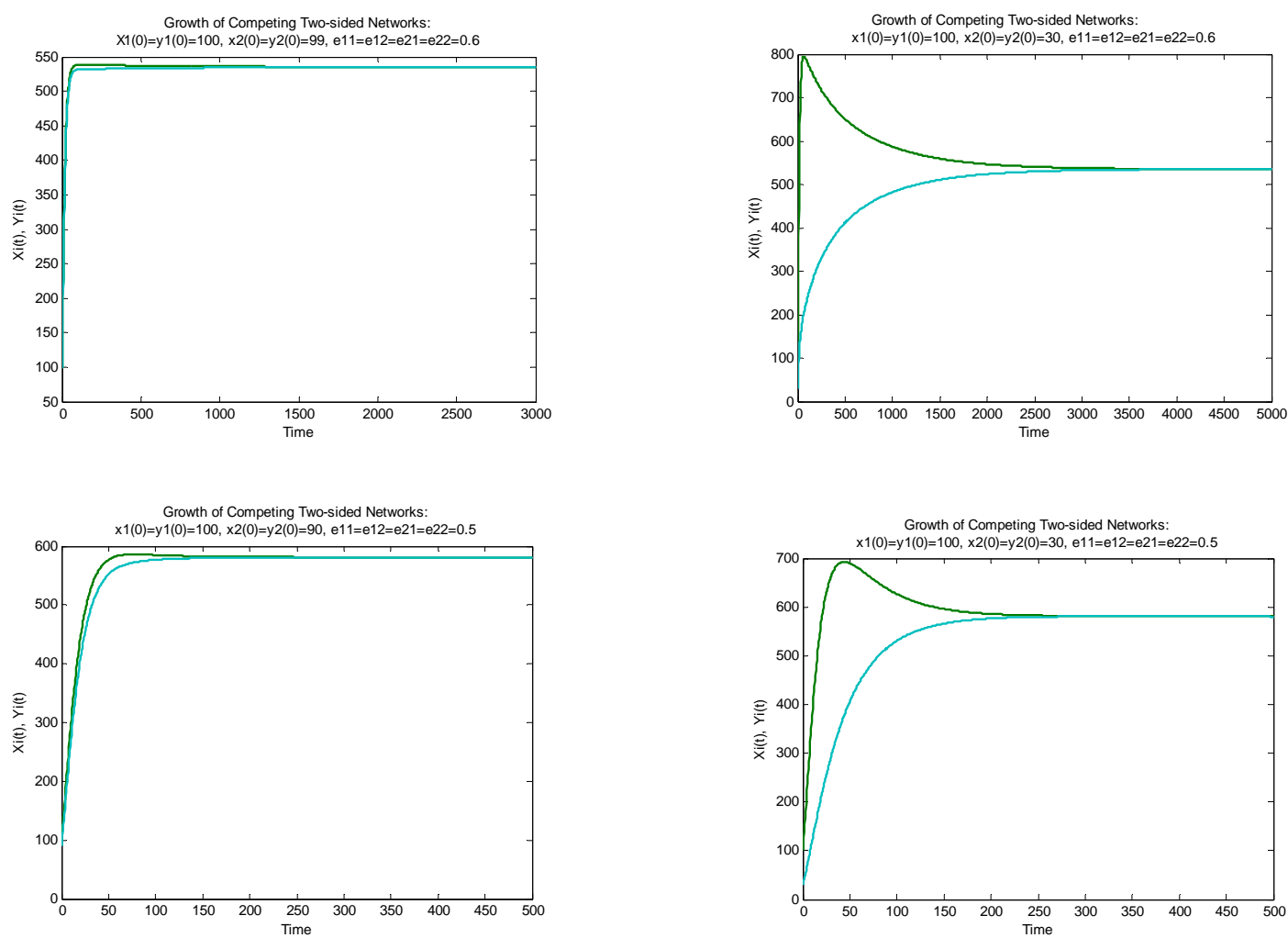

Figure 6: Growth of competing two-sided networks: Multi-homing scenario

\subsection{The impact of "network distributors"}

We now look at how different parameters affect the diffusion of the competing two-sided networks. We first consider the impact of the diffusion parameters on network diffusion. In state equations (9)-(12), the diffusion parameters are $a_{i j}, i, j=1,2$, which may differ between two competing networks due to reasons such as information dissemination, technical constraints, network coverage or availability, etc. Since advertising and "wordof-mouth effects" may affect the information available to potential participants, they are factors that may affect the diffusion parameters.

Another factor with even larger influence on the diffusion parameters is the number of distributors of a network. As discussed earlier, distributors provide network-specific products or services to network participants. Intuitively, the existence of a large number of distributors helps a network diffuse much faster than "selling" the network products/services by the network sponsor alone because of the collective efforts made by the distributors in advertising, in signing-up the participants on either or both sides of the market, in providing better or added features of the network products/services, as well as in generating larger "word-of-mouth effects". The intuition is confirmed by the following simulations based on the differential games model.

In Figure 7, we present the optimal growth paths of two competing networks when one network has larger diffusion parameters on both sides of the market than the other. The left chart is the growth paths in the single-homing scenario and the right is for the multihoming scenario. It can be seen that although the two networks start at the same initial 
conditions, the one with larger diffusion parameters grows much faster. In the singlehoming scenario, the one with smaller diffusion parameters eventually becomes a negligible player in the market, while in the multi-homing scenario, it can only capture about $30 \%$ of the market share.
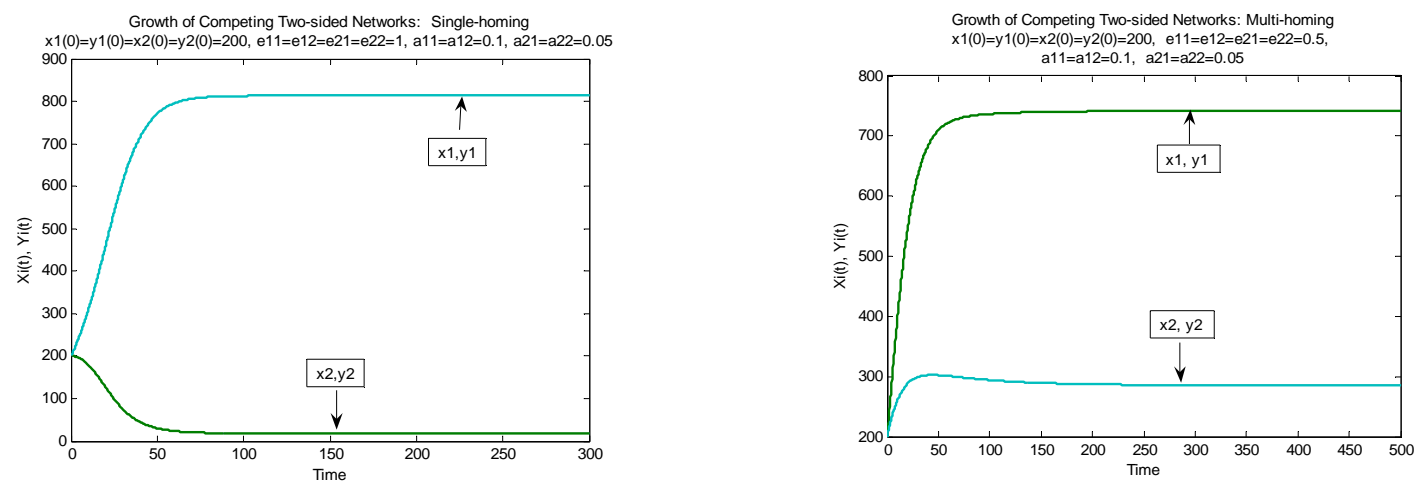

Figure 7: The impact of diffusion parameters on network competition
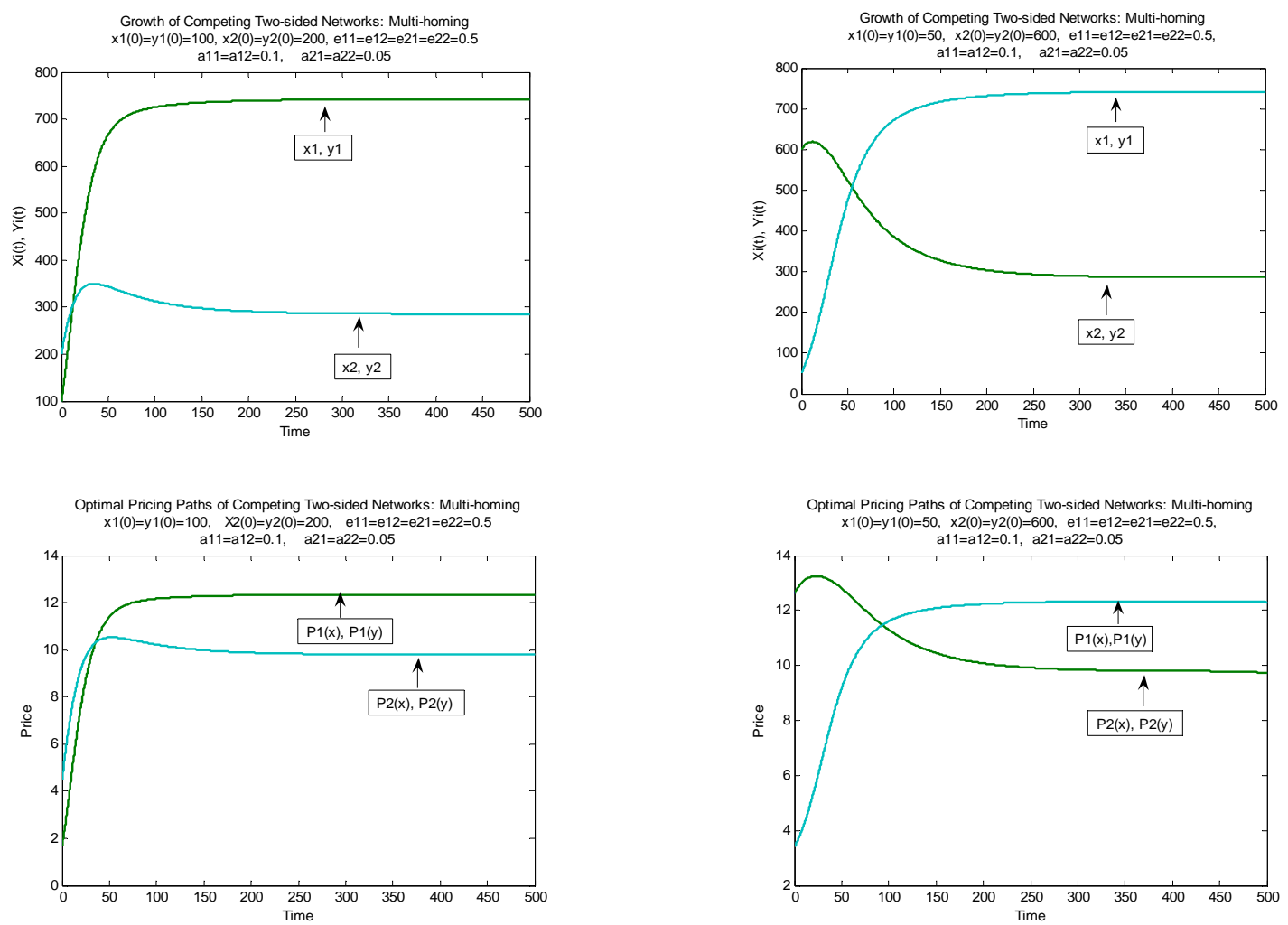

Figure 8: The impact of diffusion parameters on network competition: Multi-homing 

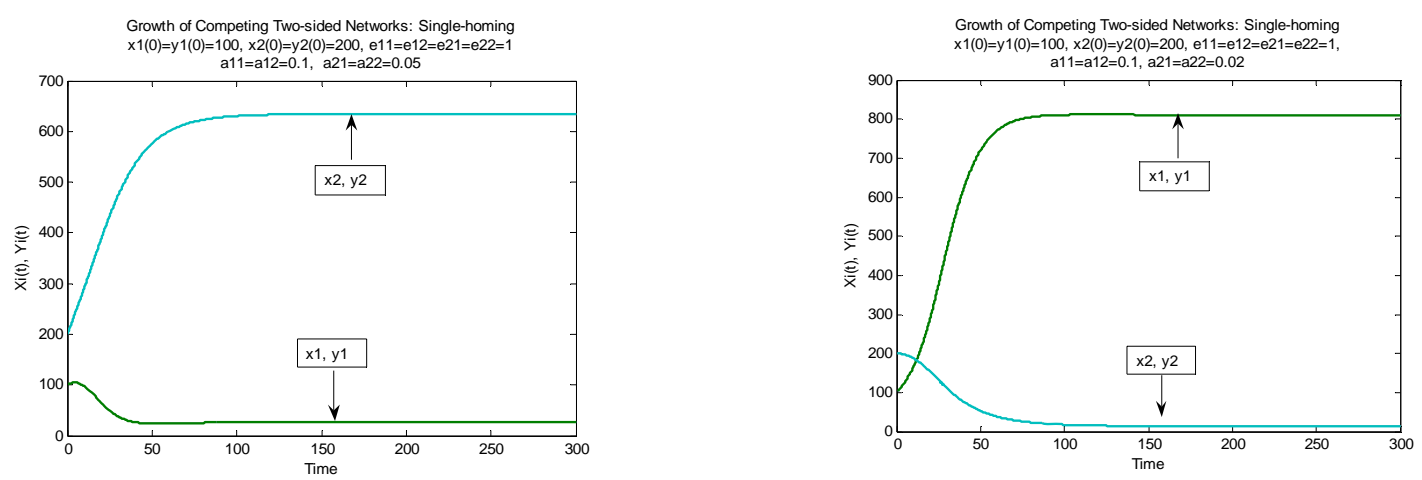

Figure 9: The impact of diffusion parameters on network competition: Single-homing

An interesting comparison is to see the relative importance of diffusion speed as compared to initial conditions. In Figure 8, we show two scenarios in the multi-homing markets. The left chart shows two networks starting from different initial sizes with one being twice the size of the other. But the smaller network has diffusion parameters that are twice the numbers of the larger network. In the long-run, the smaller network with larger diffusion parameters will surpass the initially larger network and become the dominating one. Even when the gap between the initial sizes of the two competing networks is enlarged to more than ten times, the long-term result does not change much. In other words, in multi-homing two-sided markets, diffusion parameters seem to play a more important role than initial conditions!

The optimal pricing paths shown in Figure 8 suggest that the platform sponsor with larger initial network size but slower diffusion speed tends to raise prices at the beginning of the game to maximize total profits, given that the number of participants responds slowly to higher prices due to the slow diffusion speed. On the other hand, the network with faster diffusion speed but smaller size charges low prices initially, but eventually charges a higher prices when it exceeds the other network in size, since the larger customer base enables it to charge a premium over its competitors then.

However, the situation changes in the single-homing scenario. In Figure 9, the left chart describes the growth of the same two networks as in the top-left chart of Figure 8, except that the two networks are in a market where both sides of the market tend to singlehome ( $e_{i j}=1, i, j=1,2$ in Figure 9 versus $e_{i j}=0.5, i, j=1,2$ in Figure 8). In contrast to the result in the multi-homing scenario, the network with larger initial condition becomes the one that completely dominate the market the long-run. In other words, the diffusion speed is not fast enough for the smaller network to surpass the larger network as the dominating one. The situation changes when the smaller network has diffusion parameters that are five times larger than the larger one: it will quickly surpass the larger one and become the dominating network. The findings suggest that initial conditions are much more important in determining the long-run competition outcome in single-homing case than in multihoming scenario.

The importance of diffusion speed, thus of the role of distributors, on steady-state market share has been testified in many two-sided markets. For example, before the launch of the VISA and MasterCard in 1970s, American Express was the largest payment card network in the U.S. VISA and MasterCard, which had lots of member banks issuing cards to customers and played the roles of distributors, both grew much faster than American Express. Today, American Express only captures $17.1 \%$ of market share in transaction 
volume, while VISA and MasterCard captures 51\% and 26\% respectively. ${ }^{1}$ A similar situation happened in the PC OS market where Apple's Macintosh lost to Microsoft Windows because the former had no $3^{\text {rd }}$ party distributors while the latter had many. As a result of slower diffusion, Apple now only captures about 2-3\% of the market share while Windows captures more than $90 \% .^{2}$

\subsection{The impact of product quality}

We also look at the impact of product quality on the long-term competition outcome. Figure 10 gives optimal network growth paths when two competing networks start with the same initial conditions but different product benefit parameters $\left(b_{i j}=1, i, j=1,2\right.$ in state equations (9)-(12)). The left chart refers to single-homing scenario while the right to multihoming scenario. In both cases, the network with larger product benefit parameters becomes dominating.

Similar to the findings in the previous section, product benefit parameters seem to play a more important role than initial conditions when both sides of the market multi-home. This is shown in Figure 11 where a network starts with a larger initial size but an inferior product eventually loses the market to the rival network which starts at a smaller size but having superior products/services. Even if the initial size gap is large, superior products can help a smaller network to overcome the latecomer disadvantage (refer to the left chart in Figure 11).

When both sides of the market single-home, initial conditions become more important. In the left chart of Figure 12, the smaller network eventually loses the game even if it has larger product benefit parameters. Only if the gap in the product parameters is large enough, such as those shown in the right chart of Figure 12, will it be possible for the smaller network to overcome the latecomer disadvantage by leveraging on superior products/services.

There are many real cases where product differences helped entrants to win the competition in two-sided markets. For example, in the VCR format war, the two-hour recording length of VHS is a more appealing feature to Hollywood studios, video rental stores as well as consumers than the one-hour feature of the Betamax format. Even though Betamax was the first mover, it eventually lost to VHS due to people's strong preference for longer recording time. In the video game console market, Sony turned itself from a latecomer to a dominant player by successfully introducing CD-based game console (PlayStation in 1995) and DVD-based game console (PlayStation 2 in 2000) which provided much better functionality than competitors' game consoles based on cartridges and $\mathrm{CD}$, respectively.

The findings suggest that high product quality can help a small network to overcome its size disadvantage as compared to a large network, and the impact of the product quality is more effective in multi-homing markets than in single-homing ones.

\footnotetext{
1 Data Source: VISA USA website http://www.usa.visa.com/about_visa/newsroom/statistics/

2 Data Source: “New mantra for PC makers: Diversify”, by Ina Fried from CNET News.com website: http://news.com.com/2100-1040-1027370.html
} 

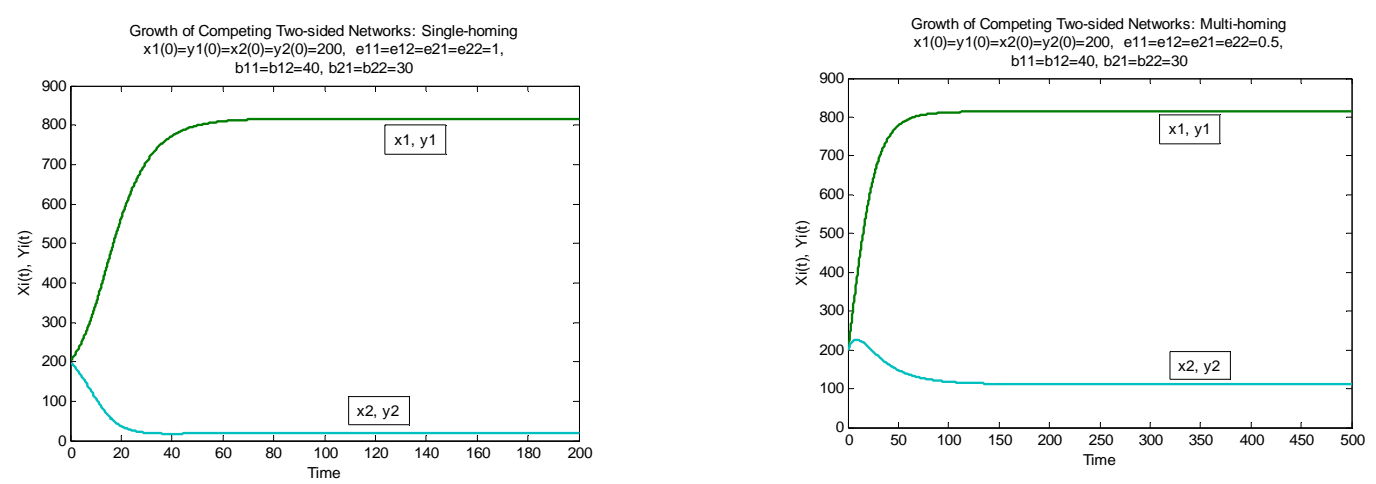

Figure 10: The impact of product parameters on network competitions
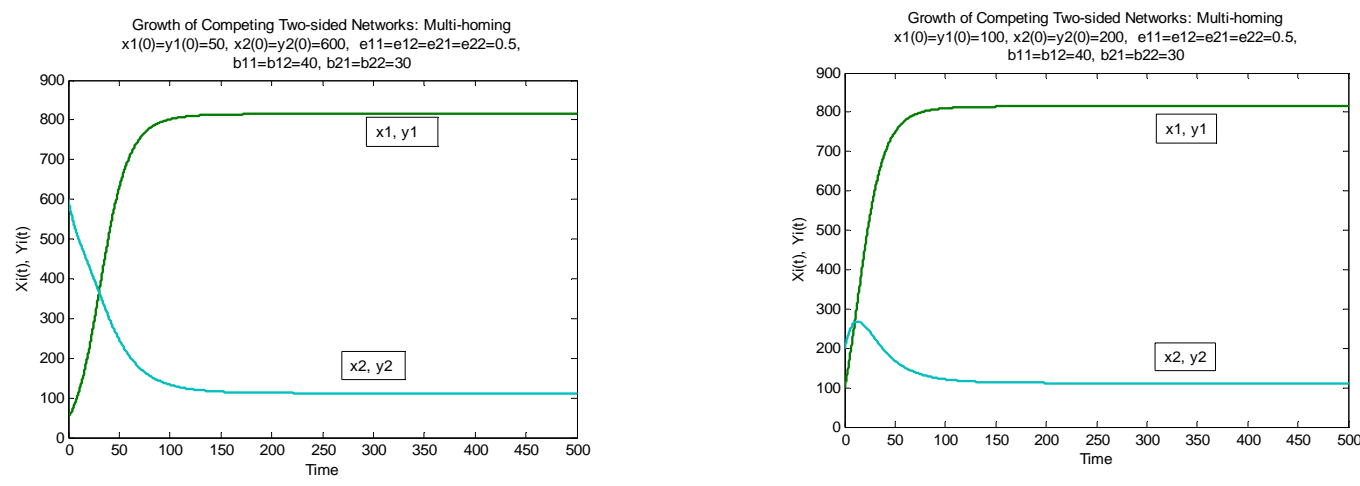

Figure 11: The impact of product parameters on network competitions: Multihoming
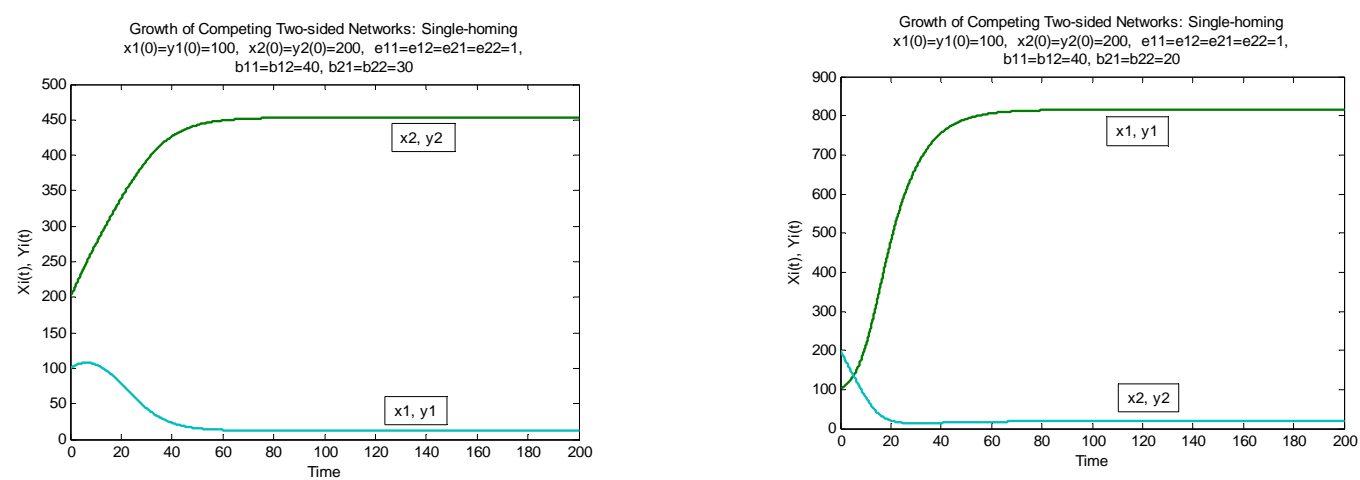

Figure 12: The impact of product parameters on network competitions: Singlehoming 


\section{Conclusion and discussion}

In this paper, we use a differential games model to study the steady-state market share of competing two-sided networks and examine under what conditions competing networks can co-exist. The model shows that, if participants tend to single-home, it is most likely that one network will dominate the market; as the tendency for single-homing increases, the likelihood for a smaller network to survive and co-exist with the larger one decreases. In other words, we are most likely to see "the-winner-takes-all" in single-homing markets and network coexistence in multi-homing ones.

Participants' tendency to single-homing not only affects the steady-state market share of the competing networks, but also the diffusion process. When participants tend to single-home and the two competing networks starts with unequal sizes, the steady-states of the two networks diverges: one network will end up with much larger market share than the other even if the initial difference is small. When participants tend to multi-home and the two competing networks starts with unequal sizes, the steady-states of the two networks converge to each other. But the speed of convergence is faster when the tendency to multi-homing is higher.

The model also reveals the role of distributors and product quality in helping network diffusion. Their roles are particularly important in markets where both sides of the market multi-home, while in single-homing markets, first-mover advantage can be more easily maintained.

The findings suggest that empirical analysis of the competition among two-sided networks may arrive at very different conclusions depending on (i) whether the networks attract primarily single-homing or multi-homing participants; and (ii) at which point on the dynamic path the empirical data is observed. The findings also indicate that, though static equilibrium models on two-sided markets may find market equilibrium similar to the steady-states in the dynamic models, their insights may be of limited importance if the adjustment process takes extremely long time. In that case, the equilibrium or steady-states have little practical significance because they are unlikely to be seen in reality.

The findings of the models have interesting strategic implications for sponsors of twosided networks. The prospect of one dominating network in the single-homing scenario may send a warning message to potential network sponsors before they enter certain twoside markets such as PC operating system, VCR format, typewriter keyboard standard, etc. Unless they have superior technologies compared to the existing ones, it is very hard for them to succeed in the market as latecomers. On the other hand, if the markets they enter involve multi-homing participants, such as the credit card payment network, yellow directory, etc., the likelihood of success will be much larger.

In the differential game models, we have considered pricing as the only control variable. In reality, most of the networks invest heavily on $R \& D$ in order to win the competition by superior products. They also spend lots of money on advertising, marketing and promotion in order to improve information availability and reduce people's adoption inertia. Thus, competing networks not only have controls over pricing, but also over other variables such as product and diffusion parameters in our model. In addition, a participant's single-homing or multi-homing behaviour may also be endogenously determined by prices, costs of participation and the requirement of exclusive contracts by network platform sponsors. Therefore, an even more realistic differential game model may include more control variables than just pricing. Unfortunately, such a model will be even 
more complex than the current one and will be extremely hard to solve even using numerical methods. However, a practical way is to change the control variables from prices to product or diffusion parameters one at a time. By this way, we can examine whether the conclusions of this paper still holds when the competition is not on pricing but on product, technology, or marketing mix variables. We leave these issues as future research topics.

An important limitation of our model is the specificity of the functional forms for the potential demand functions. Given the complexity of the differential games involved in two-sided network competition, it is almost impossible to conceive a model that is simple enough to allow for an explicit solution. Even to find the optimality condition for Nash Equilibrium, which is necessary for simulating the differential games, is a difficult task given the number of differential equations involved. Therefore, we have to choose a functional form that not only satisfies the main characteristics of the demand function, but also allows feasible numerical solutions. We view our work as only tentative in demonstrating the importance of single-homing to network competition equilibrium, and further exploration of different approaches and functional forms is definitely an important future research direction.

Finally, the differential game approach provides a suitable tool for us to study the cross-subsidization phenomenon (that is, charging high prices on one side and low prices on the other) that are often observed in two-sided markets. While Caillaud and Jullien (2001, 2003) have explored this matter, the differential game approach may provide a better framework to examine what parameters affect the emergence of such pricing behaviour. We believe that this is an interesting area which deserves further exploration.

\section{$6 \quad$ References}

Anderson, S. P. and S. Coate (2005) "Market Provision of Broadcasting: A Welfare Analysis,” Review of Economic Studies, 72: 947-972.

Armstrong, M. (2002) "The Theory of Access Pricing and Interconnection," in Cave, M., Majumdar, S. and I. Vogelsang (ed.), Handbook of Telecommunications Economics: Volume I. North-Holland: Amsterdam.

Armstrong, M. (2006) “Competition in Two-sided Markets," Rand Journal of Economics (forthcoming).

Armstrong, M. and J. Wright (2007) "Two-sided Markets, Competitive Bottlenecks and Exclusive Contracts,” forthcoming, Economic Theory.

Caillaud, B. and B. Jullien (2001) "Competing Cybermediaries," European Economic Review (Papers and Proceedings), 45: 797-808.

Caillaud, B. and B. Jullien (2003) “Chicken and Egg; Competing Matchmakers,” Rand Journal of Economics, 34: 309-328.

Carrol, P. (1993) Big Blues: The Unmaking of IBM. Crown Publishers: New York. 
David, P. A. (1985) "Clio and the Economics of QWERTY,” American Economic Review, 75: 332-337.

Dhebar, A. and S. S. Oren (1985) "Optimal Dynamic Pricing for Expanding Networks," Marketing Science, 4: 336-351.

Dhebar, A. and S. S. Oren (1986) "Dynamic Nonlinear Pricing in Networks with Interdependent Demand,” Operations Research, 34: 384-394.

Dockner, E. J., S. Jorgensen, N. Van Long and G. Sorger (2000) Differential Games in Economics and Management Science. Cambridge University Press: Cambridge, U.K.

Dukes, A. (2003) “The Advertising Market in a Product Oligopoly,” Journal of Business Economics, 52: 327-348.

Dukes, A. and E. Gal-Or (2003) "Negotiation and Exclusivity Contracts for Advertising," Marketing Science, 22: 222-245.

Edstrom, J. and M. Eller (1998) Barbarians Led by Bill Gates. Henry Holt and Company, Inc.: New York.

Evans, D. (2003a) “The Antitrust Economics of Multi-sided Platform Markets,” Yale Journal of Regulation, 20: 325-382.

Evans, D. (2003b) “Some Empirical Aspects of Multi-sided Platform Competition," Review of Network Economics, 2: 191-209.

Farrell, J. and G. Saloner (1985) "Standardization, Compatibility, and Innovation," Rand Journal of Economics, 16: 70-83.

Katz, M. and C. Shapiro (1985) "Network Externalities, Competition, and Compatibility," American Economic Review, 75: 424-440.

Parker, G. G. and M. W. Van Alstyne (2005) "Two-sided Network Effects: A Theory of Information Product Design,” Management Science, 51: 1494-1504.

Pashigan, P., E. Gould and C. Prendergast (2002) "Contracts, Externalities, and Incentives in Shopping Malls,” Working Paper, Center for Economic Policy Research, London, U.K.

Rochet, J. and J. Tirole (2002) "Cooperation among Competitors: The Economics of Payment Card Associations,” Rand Journal of Economics, 33: 1-22.

Rochet, J. and J. Tirole (2003) "Platform Competition in Two-sided Markets," Journal of the European Economic Association, 1: 990-1029.

Rochet, J. and J. Tirole (2006) “Two-sided Markets: A Progress Report,” forthcoming, Rand Journal of Economics.

Roson, R. (2005) “Two-sided Markets: A Tentative Survey,” Journal of Network Economics, 4: 142-160. 
Rysman, M. (2004) "Competition between Networks: A Study of the Market for Yellow Pages,” Review of Economic Studies, 71: 483-512.

Schiff, A. (2003) "Open and Closed Systems of Two-sided Networks," Information Economics and Policy, 15: 425-442.

Schmalensee, R. (2002) "Payment Systems and Interchange Fees," Journal of Business Economics, 50: 103-122.

Shapiro, C. and H. R. Varian (1999) Information Rules: A Strategic Guide to the Network Economy. Harvard Business School Press: Cambridge.

Shy, O. (2001) The Economics of Network Industries. Cambridge University Press: Cambridge, U.K.

Sun, M. (2006) Dynamic Network Platform Competition in Two-sided Markets. Ph.D dissertation, Stanford University.

Sun, M. and E. Tse (2006) “The Diffusion of Competing Technology Standards," in K. M. Weaver (ed.), Proceedings of the Sixty-fifth Annual Meeting of the Academy of Management (CD), ISSN 1543-8643.

Sun, M. and E. Tse (2007) "Sustainable Growth of Payment Card Networks: A Two-sided Market Approach,” forthcoming, Journal of Business Strategies.

Wright, J. (2002) "Access Pricing under Competition: An Application to Cellular Networks,” Journal of Industrial Economics, 50: 289-316.

Wright, J. (2003a) “Optimal Card Payment Systems,” European Economic Review, 47: 587-612.

Wright, J. (2003b) "Pricing in Debit and Credit Card Schemes," Economic Letters, 80: 305-309.

Wright, J. (2004) “The Determinants of Optimal Interchange Fees in Payment Systems,” Journal of Business Economics, 52: 1-26.

Xie, J. and M. Sirbu (1995) "Price Competition and Compatibility in the Presence of Positive Demand Externalities,” Management Science, 41: 909-926. 